\title{
Clinical effects of additional use of erythritol powder air polishing device on non-surgical periodontal treatment in moderate chronic periodontitis
}

\author{
Mun-Young Lee', Eon-Jeong Park', Eun-Young Kwon², Hyun-Joo Kim¹, Ju-Youn Lee', Ji-Young Joo* \\ 'Department of Periodontology, School of Dentistry and Dental Research Institute, Pusan National University, Yangsan, \\ Republic of Korea \\ ${ }^{2}$ Dental Clinic Center, Pusan National University Hospital, Pusan, Republic of Korea
}

Purpose: The purpose of this study was to evaluate the clinical effects of erythritol powder air polishing device (EPAP) in addition to scaling and root planing (SRP) in non-surgical periodontal treatment in moderate chronic periodontitis patients. Materials and Methods: Clinical evaluation was performed at 21 sites treated with SRP (control) and 21 sites treated with the addition of SRP+EPAP (test). All examinations were performed before treatment, 1 month after treatment, and 3 months after treatment. Depth of the periodontal pocket, gingival recession, clinical attachment level, plaque index, and bleeding of probing were measured as clinical parameters. Results: In both test and control groups, there was a significant decrease in the depth of the periodontal pocket, plaque index, bleeding of probing, increased gingival recession, and gain of clinical attachment level at 1 month and 3 months after treatment. However, there was no significant clinical difference between the test group and the control group. Clinical result was improved after 1 month compared to the baseline; in contrast, results at 3 months after treatment were worse than at 1 month after treatment. Conclusion: In this study, we cannot suggest that SRP + EPAP is clinically more effective than SRP alone as nonsurgical periodontal treatments. Periodic periodontal therapy, at intervals of at least every three months, is important for sustaining effects of this treatment. (J Dent Rehabil Appl Sci 2018;34(1):39-45)

Key words: periodontitis; root planing; dental scaling; treatment outcome; clinical study

\begin{abstract}
서론
치주염이란 특정 미생물 또는 미생물 군에 의해 야기 된 치아 지지조직의 염증으로 치주낭 형성, 치은 퇴축 또 는 치주인대와 치조골의 점진적인 비가역적 파괴를 초래 하는 질환으로서 치아 상실을 야기하는 대표적인 질환이 다. ${ }^{1}$ 성인의 $10-15 \%$ 가 중증의 치주염, $80 \%$ 가 중등도 치 주염을 않고 있고, $10 \%$ 만이 치주적으로 건강하다는 역 학연구가 보고되었다. ${ }^{2}$ 전신 질환과의 관련성이 입증되면

*Correspondence to: Ji-Young Joo

Assistant Professor, Department of Periodontology, School of Dentistry, Pusan National University, Dental Research Institute, 20 Geumo-ro, Beomeo-ri, Mulgeum-eup, Yangsan, 50612, Republic of Korea

Tel:+82-55-360-5203, Fax: 82-55-360-5194, E-mail: joojy@pusan.ac.kr

Received: January 10, 2018/Last Revision: January 24, 2018/Accepted: January 30,2018
\end{abstract}

서 치주질환의 파급효과 및 질환의 중요성은 더욱 커졌 다. ${ }^{3}$

치주염은 치면과 구강 점막 표면에 축적된 병원성 세균 막으로부터 야기되므로, 성공적인 치주치료를 위해서는 이러한 병원성 세균막과 그로 인해 형성된 치석의 완전한 제거를 필요로 한다. 대표적인 치료법으로는 기계적으로 제거하는 방법이 있으며 수기구나 초음파 스케일러를 이 용하여 치근 표면에 부착되어 있는 세균성 산물들을 제 거한다. 기계적 접근법외에도 소독제나 국소적 항생제

Copyright(C) 2018 The Korean Academy of Stomatognathic Function and Occlusion. (c) It is identical to Creative Commons Non-Commercial License. 
를 이용하는 화학요법도 존재하나 현재까지 알려진 바로 는 치석제거 및 치근면 활택술(scaling and root planing, $\mathrm{SRP}$ )과 같은 기계적 제거법이 gold standard로 알려져 있 다. ${ }^{4}$

그러나 SRP는 치은 절개 없이 치주낭 내로 기구를 삽 입하여 치은연하 치석 제거 및 치근면 활택술을 시행하는 기법으로 술자가 잔존 치석을 시각적으로 탐지하지 못하 는 제한 점이 있다. 그러므로 시술 후 치은연하 치석 또는 불완전한 치근 활택면이 남을 가능성이 있고 특히 깊은 치주낭이나 치근 분지부에서는 더욱 그러하다. ${ }^{5,6} \mathrm{SRP}$ 술 식의 한계를 극복할 수 있는 방법이 있다면 비외과적 치 주치료의 결과를 더욱 향상 시켜서 침습적 술식인 외과적 처치의 가능성을 감소시킬 수 있을 것이다.

공기분말 연마기구는 마모성 입자가 포함된 압축 공 기를 물과 함께 치아 표면에 분사해 치근 표면을 세척하 는 기구로 1945년에 처음 소개되었다. ${ }^{7}$ 마모성 입자와 압 축된 공기와 물이 섞여서 슬러리 상태가 되어 노즐을 통 해 분사되는 방식으로 기계적으로 병원성 세균막과 치석 등의 세균성 산물과 치아 침착물들을 제거하는데 효과적 인 방법이다. ${ }^{8}$ 그러나 공기분말 연마기구의 부작용으로 폐기종 같은 합병증이 보고되기도 하였다. ${ }^{9}$ 최근 저마모 성의 erythritol이 새로운 공기분말 연마 기구의 입자로서 소개되었다. Erythritol은 세계적으로 사용되는 식품 첨 가제 및 인공 감미료로서, 화학적으로 중성이며 친수성이 고 비독성 물질로 알려져 있다. ${ }^{10}$ 또한 이 입자는 Porphyromonas gingivalis (P. gingivalis) 같은 대표적인 치주 병원균 에 항미생물 효과를 가지는 것으로 밝혀졌다. ${ }^{11}$

본 연구는 중등도 만성 치주염 환자에서 비외과적 치 주치료 시 SRP에 부가적으로 erythritol 공기분말 연마기 구를 사용하는 것의 임상적 효과를 평가해 보고자 한다.

\section{연구 재료 및 방법}

\section{1. 연구 대상}

본 연구는 2017년 3월에서 8월 사이에 부산대학교 치 과병원을 방문한 환자 중 만 19세에서 70세까지 성인 남 녀를 대상으로 다음과 같은 기준을 만족하고 자발적으 로 연구에 참여하고자 하는 환자에 한하여 시행되었으며 임상 실험 프로토콜은 부산대학교 치과병원 생명윤리심 의위원회의 승인(PNUDH-2017-006)을 받았다. 참여기 준은 1999년 미국치주학회의 질환 분류 기준에 따른 중
등도 만성치주염 환자로서 치석제거 및 치근활택술이 필 요한 환자, 치열의 중절치부터 제 2 대구치까지 잔존 치주 낭 깊이가 $4 \mathrm{~mm}$ 이상 $6 \mathrm{~mm}$ 이하인 치아를 하나 이상 가 지는 분악이 2 분악 이상인 환자이다. 제외 기준은 조절되 지 않은 전신질환이 있거나 임신, 모유수유 중인 환자, 최 근 6개월 이내 치주치료를 받은 적이 있는 환자이다. 총 21명의 환자에서 무작위 배정 및 split-mouth design으로 진행되었으며 이들은 실험에 대한 자세한 설명을 들은 후 자발적으로 참가 동의서에 서명하였다.

\section{2. 연구 방법}

연구 참여 환자의 좌우측 중절치부터 제 2 대구치까지, 치주낭 깊이가 $4 \mathrm{~mm}$ 이상 $6 \mathrm{~mm}$ 이하인 치아를 하나 이 상 가지는 2 분악을 선택하고, 한 분악은 대조군으로서 $\mathrm{SRP}$ 만으로 처치하고 다른 분악은 실험군으로서 SRP에 부가적으로 erythritol 공기분말 연마기구를 처치하였다. 이 중 치주낭 깊이가 $4 \mathrm{~mm}$ 이상 $6 \mathrm{~mm}$ 이하인 치아만 임 상 평가를 위해 다음의 임상지수들이 측정되었다.

- 치주낭 깊이(PD): 치주 탐침기를 이용하여 유리치은 변 연으로부터 치주낭 기저부까지의 거리를 측정

- 치은 퇴축(REC): 치주 탐침기를 이용하여 백악법랑경 계로부터 유리치은 변연까지의 거리를 측정

- 임상부착수준(CAL): 백악법랑경계로부터 치주낭 기저 부까지의 거리

- 치태지수(PI): 구강청결도를 의미하는 지수로서 치태의 두께에 따라 치태가 부착되어 있지 않은 상태는 0 , 치 아와 유리치은 변연에 부착된 치태로서 치주 탐침기 로 치면을 긁어보아 확인할 수 없는 엷은 상태는 1 , 치은낭과 치은변연을 따라 육안으로 확인될 수 있을 정도로 과량의 치태가 부착되어 있고 치간 사이에 치 태가 없는 상태는 2, 치은변연에 많은 양의 치태가 침 착되어 있고 치간 사이에도 치태가 채워져 있는 상태 는 3으로 구분하여 표기함.

- 탐침시 출혈(BOP): 치주 탐침 후 30 초 이내의 출혈을 관찰하여 전체 부위 중 출혈이 발생한 부위의 비율을 표기함

치태지수는 치아당 4 부위(근심협측, 협측정중부, 원심 협측, 구개/설측)에서 측정되었고 나머지 임상지표들은 치아당 6 부위(근심협측, 협측정중부, 원심협측, 근심설 측, 설측정중부, 원심설측)에서 측정되었다. 모든 측정은 치주 탐침기(PGF-W, Osung, Gwangmyeong, Korea)를 


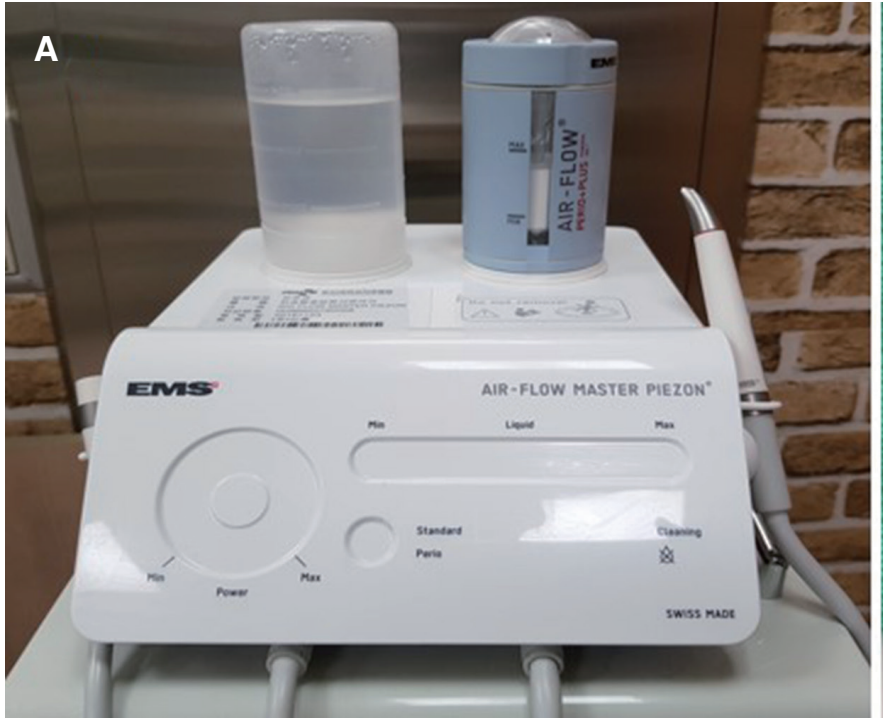

Fig. 1. (A) Erythritol powder air-polishing device,

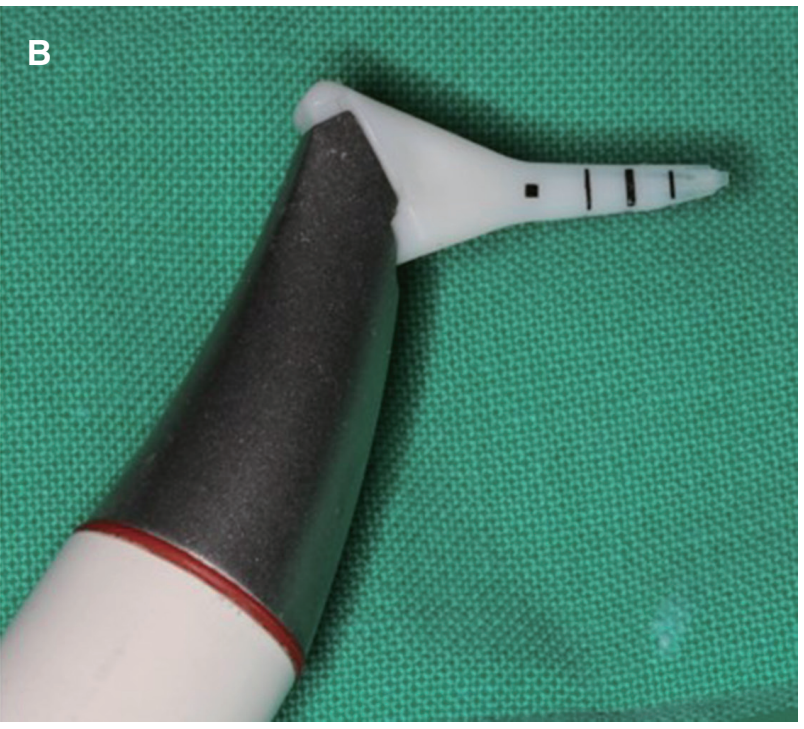

(B) Nozzle tip designed for subgingival crevice.
사용하여 $1 \mathrm{~mm}$ 단위로 반올림하여 표시하였다. 임상검 사 및 시술은 한 명의 숙달된 술자에 의해 시행되었으며, 임상지수 측정은 치료전, 치료 1 개월 및 3 개월 후 시기에 이루어졌다.

실험군과 대조군 모두 Gracey curettes (Hu-Friedy, Chicago, USA)을 이용하여 SRP가 시행되었고, 실험군 에는 부가적으로 erythritol 입자를 적용한 공기분말 연 마기구(Air-Flow Master with Perio-Flow System, EMS, Geneva, Swiss)를 제조사의 지시에 따라 5 초간 해당 치 아에 적용하였다(erythritol powder air-polishing device, EPAP). 치은연하에 적용 가능하도록 고안된 노즐 팁을 치주낭에 삽입하여 치근 표면에 수직으로 분사하였다 (Fig. 1).

\section{3. 통계분석}

실험군과 대조군의 치주 치료 전후의 임상 지수는 평균 과 표준편차로 표시하였다. 각 그룹의 치료 전과 치료 1 개월 및 3 개월 후의 임상지수는 일원배치 분산분석을 통 해 분석되었고, Tukey Honestly Significant Difference Test를 통해 사후 검정되었다. 실험군과 대조군 간의 임 상지수 비교는 독립 t-test를 통해 분석되었다. 유의 수 준은 0.05로 설정하였으며 통계분석은 SPSS 21.0버전 (IBM SPSS Inc., Chicago, USA)을 이용하였다.

\section{결과}

실험에 포함되어 처치 받은 치아는 실험군에서 152개, 대조군에서 151 개였으나 임상적 유효성 평가는 치주낭 깊이가 $4 \mathrm{~mm}$ 이상 $6 \mathrm{~mm}$ 이하인 치아만 시행했으며 실 험군 85 개, 대조군에서 83 개였다. 평가한 치아의 분포는 실험군과 대조군에서 균일하게 분배되었다(Table 1).

실험군과 대조군 모두에서 치료 전에 비해 치료 1 개월 후, 3 개월 후 치주낭 깊이, 치태지수, 탐침시 출혈의 유의 한 감소가 관찰되었으며 치은 퇴축의 증가 및 임상부착 수준의 유의한 획득을 얻을 수 있었다. 그러나 실험군과 대조군 간에 임상지수들의 변화에는 유의한 차이가 관찰 되지 않았다. 치료 3 개월 후 모든 임상지수들은 치료 전 에 비해서는 개선되었으나 치료 1 개월 후에 비해서는 악 화되었다(Table 2).

\section{고찰}

공기분말 연마기구는 자연치아의 세균성 치태와 치석 등의 침착물을 제거하기 위해 처음 고안된 제품이나 현 재는 감염된 임플란트 표면의 해독을 위해 널리 이용되 고 있다. ${ }^{12}$ 최근 항미생물 효과를 가지면서 낮은 마모성 의 수용성 입자인 erythritol 입자가 공기분말 연마기구 에 적용되므로써, 치주염 치료완료 후 유지기 환자에서 
Table 1. Distribution among tooth groups in test and control group

\begin{tabular}{lccc}
\hline & SRP & SRP + EPAP & P \\
\hline Total number of treated tooth with PD $\geq 4 \mathrm{~mm}$ & 83 & 85 & 0.83 \\
Mean tooth number (maxilla) & & & 0.55 \\
$\quad$ incisors & 18 & 24 & 0.85 \\
$\quad$ premolars & 25 & 30 & 0.99 \\
$\quad$ molars & 30 & & 0.27 \\
Mean tooth number (mandible) & & 7 & 0.35 \\
$\quad$ incisors & 2 & 5 & 0.82 \\
$\quad$ premolars & 2 & 5 & 0.43 \\
$\quad$ molars & 6 & $3.42 \pm 0.37$ & \\
\hline
\end{tabular}

SRP: scaling and root planing, EPAP: erythritol powder air-polishing device.

Table 2. Clinical parameters at baseline, 1 month and 3 months after treatment (mean \pm SD)

\begin{tabular}{|c|c|c|c|c|c|c|c|c|c|}
\hline & \multicolumn{4}{|c|}{ SRP } & \multicolumn{4}{|c|}{ SRP + EPAP } & \multirow[b]{2}{*}{$P^{\dagger}$} \\
\hline & Baseline & $1 \mathrm{mc}$ & $3 \mathrm{mc}$ & $P^{*}$ & Baseline & $1 \mathrm{mc}$ & $3 \mathrm{mc}$ & $P^{*}$ & \\
\hline PI (index) & $\begin{array}{c}2.32 \\
( \pm 0.22)\end{array}$ & $\begin{array}{c}0.59 \\
( \pm 0.18)\end{array}$ & $\begin{array}{c}0.90 \\
( \pm 0.18)\end{array}$ & 0.00 & $\begin{array}{c}2.27 \\
( \pm 0.25)\end{array}$ & $\begin{array}{c}0.62 \\
( \pm 0.15)\end{array}$ & $\begin{array}{c}1.04 \\
( \pm 1.72)\end{array}$ & 0.00 & 0.61 \\
\hline $\mathrm{BOP}(\%)$ & $\begin{array}{c}41.19 \\
( \pm 16.48)\end{array}$ & $\begin{array}{c}12.89 \\
( \pm 7.95)\end{array}$ & $\begin{array}{c}14.68 \\
( \pm 9.01)\end{array}$ & 0.00 & $\begin{array}{c}43.55 \\
( \pm 15.52)\end{array}$ & $\begin{array}{c}15.74 \\
( \pm 13.33)\end{array}$ & $\begin{array}{c}16.41 \\
( \pm 9.34)\end{array}$ & 0.00 & 0.89 \\
\hline $\mathrm{PD}(\mathrm{mm})$ & $\begin{array}{c}3.49 \\
( \pm 0.41)\end{array}$ & $\begin{array}{c}2.65 \\
( \pm 0.23)\end{array}$ & $\begin{array}{c}2.77 \\
( \pm 0.19)\end{array}$ & 0.00 & $\begin{array}{c}3.39 \\
( \pm 0.37)\end{array}$ & $\begin{array}{c}2.49 \\
( \pm 0.13)\end{array}$ & $\begin{array}{c}2.79 \\
( \pm 0.43)\end{array}$ & 0.00 & 0.29 \\
\hline CAL (mm) & $\begin{array}{c}3.93 \\
( \pm 0.63)\end{array}$ & $\begin{array}{c}3.33 \\
( \pm 0.50)\end{array}$ & $\begin{array}{c}3.56 \\
( \pm 0.56)\end{array}$ & 0.01 & $\begin{array}{c}3.99 \\
( \pm 0.74)\end{array}$ & $\begin{array}{c}3.37 \\
( \pm 0.62)\end{array}$ & $\begin{array}{c}3.45 \\
( \pm 0.63)\end{array}$ & 0.01 & 0.47 \\
\hline $\operatorname{Rec}(\mathrm{mm})$ & $\begin{array}{c}0.44 \\
( \pm 0.50)\end{array}$ & $\begin{array}{c}0.68 \\
( \pm 0.54)\end{array}$ & $\begin{array}{c}0.78 \\
( \pm 0.55)\end{array}$ & 0.10 & $\begin{array}{c}0.59 \\
( \pm 0.55)\end{array}$ & $\begin{array}{c}0.88 \\
( \pm 0.56)\end{array}$ & $\begin{array}{c}0.89 \\
( \pm 0.62)\end{array}$ & 0.18 & 0.68 \\
\hline
\end{tabular}

PI: plaque index, BOP: bleeding on probing, PD: probing depth, CAL: clinical attachment level, Rec: recession, SRP: scaling and root planing, EPAP: erythritol powder air-polishing device.

*Statistically significant difference of clinical index among at the baseline and at the 1 -month check $(1 \mathrm{mc})$ and at the 3 -month check $(3 \mathrm{mc})$ using one-way ANOVA $(P<0.05)$.

† No significant difference of clinical parameters change between SRP and SRP + EPAP group using independent t-test from baseline to 3-month $\operatorname{check}(3 \mathrm{mc})(P=0.05)$.

치은연상 및 치은연하 치태의 제거에 SRP와의 효과 비 교 논문이 있었다. ${ }^{13}$ 치주염 치료를 위한 대표적인 비외 과적 처치인 SRP가 맹검기법이라는 한계점을 극복하기 위해 본 연구에서는 치주염 치료기에 SRP에 부가적으로 erythritol 공기분말 연마기구를 적용함으로써 임상적 효 과를 분석해 보았다.

본 연구는 SRP치료에 가장 적합한 부위인 중등도 만성 치주염 환자에서 $4 \mathrm{~mm}$ 에서 $6 \mathrm{~mm}$ 의 치주낭을 가지는 치 아를 상대로 평가되었다. SRP만 시행한 대조군과 SRP에 부가적으로 $\mathrm{EPAP}$ 를 적용한 실험군을 치료전, 치료 후 1
개월 및 3 개월까지 경과를 관찰한 결과 두 치료 모두에서 치료 전에 비해 치료 후에 치주낭 깊이, 치태지수, 탐침시 출혈의 유의한 감소가 관찰되었고 치은퇴축의 증가 및 임상부착수준의 유의한 획득을 보여주어 단기간 임상적 으로 효과를 가지는 치료임을 보여주었다. 그러나 두 집 단간 임상 지수의 통계적 유의성이 관찰되지 않아 EPAP 를 부가적으로 사용하는 것이 SRP만 시행하는 것에 비 해 더 효과적이라고 제안할 수는 없다. 이는 유지치료기 에서 EPAP를 SRP와 비교하였던 Hägi 등 ${ }^{13}$ 의 논문과도 일치하였다. 
치료 3개월 후 모든 임상지수들은 치료 전에 비해서는 개선되었으나 치료 1 개월 후에 비해서는 악화되었다. 이 는 치주치료 후 치주조직 건강을 유지하기 위해서 보조 적인 치주처치가 정기적으로 필요하다는 수많은 치주학 분야 임상 연구들의 결과와 일치하였다. ${ }^{14}$

그러나 임상연구를 진행하는 동안 공기분말 연마기 구의 부작용으로 알려진 폐기종 같은 합병증은 발생되 지 않았다. 기존의 마모성이 높다고 알려진 입자들에 비 해 저마모성의 erythritol 입자를 사용한 경우에는 폐기종 은 아주 적은 발생율이 보고되었다. ${ }^{15}$ 이는 저마모성이라 는 입자 특성 때문에 치은 열구의 세척이 부드럽게 행해 지고, 치은연하 적용을 위해 특별히 고안된 노즐의 발전 을 통해, air jet가 치근 표면에 수직적으로 적용될 수 있 으므로 인접한 치주조직에 불필요하게 적용되는 압력을 피할 수 있으므로 폐기종의 발생율을 감소시키는 것으로 생각된다. 또한 erythritol 입자는 Hashino 등 ${ }^{11}$ 의 미생물 학적 연구에서 P. gingivalis의 증식억제 효과를 보이고 $P$. gingivalis로 구성된 biofilm의 미세구조와 대사형태를 변 형시키므로써 억제효과를 가진다고 밝혀졌다.

따라서 erythritol 공기분말 연마기구는 중등도 만성 치 주염 환자에서 비외과적 치주염 치료에 효과적으로 적용 될 수 있으나 SRP에 부가적으로 적용할 시 SRP 단독과 비교하였을 때 임상적으로 더 효과적이라고 제안할 수는 없다. 그러나 erythritol 입자가 치주염 발병에 중요한 세 균인 P. gingivalis 억제 효과를 가진다고 알려져 있으므로 임상 적용 후 치은연하 환경의 미생물 분석을 추가로 시 행해 보면 의미 있는 결과가 나올 것으로 사료되어 후속 연구로 제안된다.

\section{결론}

중등도 만성 치주염 환자의 비외과적 치주치료 시 erythritol 공기분말 연마기구는 부가적으로 적용될 수 있으나 SRP 단독과 비교하였을 때 임상적으로 더 효과 적이라고 제안할 수는 없다. 또한 최소 3 개월 간격의 주 기적인 유지관리 치료가 필요함을 알 수 있다.

\section{Acknowledgements}

이 논문은 부산대학교 기본연구지원사업(2년)에 의하 여 연구되었음.

\section{ORCID}

Mun-Young Lee https://orcid.org/0000-0002-1896-7493

Eon-Jeong Park https://orcid.org/0000-0002-9906-587X

Eun-Young Kwon https://orcid.org/0000-0001-95550360

Hyun-Joo Kim https://orcid.org/0000-0001-7553-6289

Ju-Youn Lee https://orcid.org/0000-0002-0772-033X

Ji-Young Joo https://orcid.org/0000-0002-4050-5797

\section{References}

1. Heitz-Mayfield LJ, Trombelli L, Heitz F, Needleman I, Moles D. A systematic review of the effect of surgical debridement vs non-surgical debridement for the treatment of chronic periodontitis. J Clin Periodontol 2002;29 Suppl 3:92-102.

2. Locker D, Slade GD, Murray H. Epidemiology of periodontal disease among older adults: a review. Periodontol 2000 1998;16:16-33.

3. Lindhe J, Karring T, Lang NP. Clinical periodontology and implant dentistry. 4th ed. Oxford; Blackwell Munksgaard; 2003. p. 366-70.

4. Drisko CH. Nonsurgical periodontal therapy. Periodontol 2000. 2001;25:77-88.

5. Eaton KA, Kieser JB, Davies RM. The removal of root surface deposits. J Clin Periodontol 1985;12: 141-52.

6. Fleischer HC, Mellonig JT, Brayer WK, Gray JL, Barnett JD. Scaling and root planing efficacy in multirooted teeth. J Periodontol 1989;60:402-9.

7. Black R. Technic for nonmechanical preparation of cavities and prophylaxis. J Am Dent Assoc 1945:32: 955-65.

8. Petersilka GJ. Subgingival air-polishing in the treatment of periodontal biofilm infections. Periodontol 2000 2011;5:124-42.

9. Finlayson RS, Stevens FD. Subcutaneous facial emphysema secondary to use of the Cavi-Jet. J Periodontol 1988;59:315-7.

10. Hägi TT, Hofmänner P, Salvi GE, Ramseier CA, Sculean A. Clinical outcomes following subgingival application of a novel erythritol powder by means of air polishing in supportive periodontal therapy: a 
randomized, controlled clinical study. Quintessence Int 2013;44:753-61.

11. Hashino E, Kuboniwa M, Alghamdi SA, Yamaguchi M, Yamamoto R, Cho H, Amano A. Erythritol alters microstructure and metabolomic profiles of biofilm composed of Streptococcus gordonii and Porphyromonas gingivalis. Mol Oral Microbiol 2013;28: 435-51.

12. John G, Sahm N, Becker J, Schwarz F. Nonsurgical treatment of peri-implantitis using an air-abrasive device or mechanical debridement and local application of chlorhexidine. Twelve-month followup of a prospective, randomized, controlled clinical study. Clin Oral Investig 2015;19:1807-14.

13. Hägi T'T, Hofmänner P, Eick S, Donnet M, Salvi GE, Sculean A, Ramseier CA. The effects of erythritol air-polishing powder on microbiologic and clinical outcomes during supportive periodontal therapy: six-month results of a randomized controlled clinical trial. Quintessence Int 2015;46:3141.

14. Renvert S, Persson GR. Supportive periodontal therapy. Periodontol 2000 2004;36:179-95.

15. Petersilka G. Letter to the editor: Re: "Subgingival plaque removal using a new air-polishing device". J Periodontol 2010;81:962-3. 


\section{중등도 만성 치주염 환자에서 erythritol 공기분말 연마기구를 부가적으로 이용 하는 비외과적 치주치료의 임상적 효과}

\section{이문영 ${ }^{1}$, 박언정 ${ }^{1}$, 권은영 ${ }^{2}$, 김현주 ${ }^{1}$, 이주연 ${ }^{1}$, 주지영 ${ }^{1 *}$}

${ }^{1}$ 부산대학교 치의학전문대학원 치주과학교실

${ }^{2}$ 부산대학교병원 치과진료센터

목적: 치석제거 및 치근면활택술(scaling and root planing, SRP)은 만성 치주염 환자에서 대표적인 비외과적 치주치료법 이나 술자가 잔존치석을 시각적으로 확인하지 못하는 한계가 있다. 본 연구는 중등도 만성 치주염 환자에서 비외과적 치 주치료 시 SRP에 부가적으로 erythritol 공기분말 연마기구를 사용하는 것의 임상적 효과를 평가해 보고자 한다.

연구 재료 및 방법: 중등도 만성 치주염을 가지는 21 명의 환자에서 비외과적 치주치료를 위해 SRP로만 치료받은 21 부위 (대조군)와 SRP에 부가적으로 erythritol 공기분말 연마기구를 사용하여 치료한 21부위(실험군)에서 4-6 mm의 치주낭 을 가지는 치아를 선택하여 평가하였다. 치료 전, 치료 완료 1 개월, 3 개월 후에 치주낭 깊이, 치은퇴축, 임상부착수준, 치 태지수, 탐침시 출혈이 임상지표로 측정되었다.

결과: 실험군과 대조군 모두에서 치료 전에 비해 치료 1 개월 후, 3 개월 후 치주낭 깊이, 치태지수, 탐침시 출혈의 유의한 감소와 치은 퇴축의 증가 및 임상부착수준의 유의한 획득이 관찰되었다. 그러나 실험군과 대조군 간에 임상지표들의 변 화에는 유의한 차이가 관찰되지 않았다. 치료 3 개월 후 모든 임상지표들은 치료 전에 비해서는 개선되었으나 치료 1 개월 후에 비해서는 악화되었다.

결론: 중등도 만성 치주염 환자의 비외과적 치주치료 시 erythritol 공기분말 연마기구는 부가적으로 적용될 수 있으나 $\mathrm{SRP}$ 단독과 비교하였을 때 임상적으로 더 효과적이라고 제안할 수는 없다. 또한 최소 3 개월 간격의 주기적인 유지관리 치료가 필요함을 알 수 있다.

(구강회복응용과학지 2018;34(1):39-45)

주요어: 치주염; 치근면 활택술; 치석제거술; 치료 결과; 임상 연구

*교신저자: 주지영

(50612)경상남도 양산시 물금읍 범어리 금오로 20 , 부산대학교 치의학전문대학원 치주과학교실, 치의학연구소

Tel: 055-360-5203 | Fax: 055-360-5194 | E-mail: joojy@pusan.ac. kr

접수일: 2018년 1월 10일 | 수정일: 2018년 1월 24일 | 채택일: 2018년 1월 30일 